\title{
UMA ANÁLISE QUALITATIVA SOBRE SEXUALIDADE E SEUS ASPECTOS BIOPSICOSSOCIAIS NA TERCEIRA IDADE
}

\author{
A QUALITATIVE ANALYSIS ON SEXUALITY AND ITS \\ BIOPSYCHOSOCIAL ASPECTS IN THE ELDERLY
}

João Pedro Arantes da Cunha ${ }^{1}$ Jordão Raphael Fujii Ramos ${ }^{2}$ Thiago Vilela de Freitas ${ }^{3}$ Ruberval Franco Maciel ${ }^{4}$

RESUMO: Introdução: $O$ aumento da expectativa e qualidade de vida transpassaram os significados de envelhecimento, levando à maior visibilidade da sexualidade e ocorrência de práticas sexuais na população idosa, tornando-as mais vulneráveis às infecções sexualmente transmissíveis (IST's). Objetivo: Analisar o processo de construção de sentidos das idosas a partir dos aspectos de letramento em saúde, relacionando à temática da sexualidade e suas repercussões biopsicossociais. Métodos: Trata-se de uma pesquisa qualitativa de natureza interpretativa e exploratória realizada com um grupo de idosas em acompanhamento em um Centro de Doenças Infecto-contagiosas. Foi priorizada uma abordagem pósestruturalista na epistemologia da emergência pós-moderna, voltando-se a perspectiva teórica para os estudos sobre letramento em saúde. Resultados: Destacam-se aspectos que emergiram: desejo sexual e impotência, comportamentos de risco inerentes às práticas sexuais apresentadas pelos idosos, baixo letramento acerca dos riscos aos quais estão expostos, negação pessoal com a prática sexual, seja por cunho religioso, ou relacionado às opiniões da família,

\footnotetext{
1 Graduando do curso de Medicina pela Universidade Estadual de Mato Grosso do Sul - UEMS, Campus Universitário de Campo Grande, Mato Grosso do Sul, Brasil. Email: jparantesdacunha@gmail.com. ID Orcid: https://orcid.org/0000-0002-3292-0210.

2 Graduando do curso de Medicina pela Universidade Estadual de Mato Grosso do Sul - UEMS, Campus Universitário de Campo Grande, Mato Grosso do Sul, Brasil. Email: jordao.fujii@terra.com.br. ID Orcid: https://orcid.org/0000-0001-7201-7328.

3 Graduando do curso de Medicina pela Universidade Estadual de Mato Grosso do Sul - UEMS, Campus Universitário de Campo Grande, Mato Grosso do Sul, Brasil. Email: thiagov_freitas@hotmail.com. ID Orcid: https://orcid.org/0000-0003-3427-9807.

${ }^{4}$ Doutor em Estudos Linguísticos e Literários de Inglês pela USP. Universidade Estadual de Mato Grosso do Sul - UEMS, Campo Grande, MS, Brasil. Email: rubervalmaciel@gmail.com. ID Orcid: https://orcid.org/0000-0003-0373-1047.
} 
medos e receios, a própria construção do senso comum e preconceitos perante a sexualidade do idoso exposto pela mídia. Conclusão: Em relação à quebra de círculo hermenêutico interpretativo, ocorreram crises em diversos pontos das conversas: a continuidade da sexualidade na terceira idade, o baixo retrato pela mídia, em relação ao conceito e percepção das práticas sexuais e prevenção das IST's na terceira idade. O tema merece maior reconhecimento, já que a prática sexual é realizada universalmente, tornando-se uma problemática de saúde coletiva, tornando-se necessário alavancar ações e estudos de educação em saúde para a população idosa.

Palavras chave: Letramento em Saúde; Saúde do Idoso; Comportamento Sexual; Sexualidade; Doenças Sexualmente Transmissíveis; Saúde Pública.

ABSTRACT: Introduction: The increase in life expectancy and quality of life crossed the meanings of aging, leading to greater visibility of sexuality and the occurrence of sexual practices in the elderly population, making them more vulnerable to sexually transmitted infections (STIS). Objective: to analyze the process of construction of meanings for elderly women from aspects of health literacy, relating to the theme of sexuality and its biopsychosocial repercussions. Methods: This is a qualitative study of an interpretative and exploratory nature carried out in a Center for Infectious Diseases with elderly people being monitored at the unit. A post-structuralist approach was prioritized in the epistemology of the postmodern emergence, turning the theoretical perspective to studies on health literacy. Results: Aspects that emerged were highlighted: sexual desire and impotence, risk behaviors inherent to sexual practices presented by the elderly, low literacy about the risks to which they are exposed, personal denial of sexual practice, whether religious or related to family opinions, fears and fears, the very construction of common sense and prejudices regarding the sexuality of the elderly exposed by the media. Conclusion: Regarding the breaking of the interpretive hermeneutic circle, crises occurred at various points in the conversations: the continuity of sexuality in old age, the low portrayal by the media in relation to the concept and perception of sexual practices and prevention of STIs in old age. The theme deserves greater recognition, as sexual practice is universally performed, becoming a collective health issue, so leverage is needed in health education actions and studies for the elderly population.

Keywords: Health Literacy; Health of the elderly; Sexual Behavior; Sexuality; Sexually Transmitted Diseases; Public health. 


\section{INTRODUÇÃO}

O aumento da expectativa e qualidade de vida transpassaram os significados de envelhecimento adotados no século anterior. O idoso, zelado como vitrine do desenvolvimento humano do país, teve a atenção em saúde pautada no tratamento das doenças crônicas não transmissíveis, mas intocável nos aspectos da sexualidade. Hoje, são visíveis os reflexos da falta de assistência integral à saúde com as pessoas da terceira idade, ganhando cada vez mais relevância o olhar sobre suas práticas sexuais para a saúde pública nacional.

No Brasil, é evidente o aumento da incidência de infecções sexualmente transmissíveis (IST's) na terceira idade, fator diretamente relacionado ao letramento em saúde precário oferecido a esta população, o que os torna vulneráveis, pairando em um cenário longe do que seria o envelhecimento saudável (FERREIRA et. al., 2019).

Nos últimos anos, houve maior enfoque no desenvolvimento das políticas nacionais de saúde em abordagem sobre sexualidade e IST's, especialmente a partir da década de 80 , com o estabelecimento de projetos como o Programa Nacional de Doenças Sexualmente Transmissíveis e AIDS, criado em 1985, e o Programa de Saúde do Adolescente, oficializado em 1988 (BRASIL 2018; BRASIL, 2020).

Esses programas trouxeram à discussão os números emergentes de IST's dentre a população brasileira, principalmente, com a disseminação do vírus HIV. A partir deles, foram estabelecidas parcerias intersetoriais e intrasetoriais, que visaram à mobilização e educação permanentes em saúde sexual e reprodutiva, visando atenção com a pluralidade e diversidade que engloba a construção sociocultural dos brasileiros (BRASIL, 2003) (MIRANDA et al, 2021).

A partir disso, houve um crescimento consistente nas ações de saúde com o objetivo de promover a saúde sexual e prevenir a transmissão de doenças através das práticas sexuais. As escolas passaram a ser um ponto-chave na 
conscientização dos futuros cidadãos, que entrariam em idade reprodutiva e, naquele momento, iniciavam as descobertas íntimas referentes ao sexo, isto é, seriam os indivíduos mais vulneráveis na sociedade pelo desconhecimento. Assim, com o estabelecimento de Diretrizes Nacionais para a Atenção Integral à Saúde de Adolescentes e Jovens na Promoção, Proteção e Recuperação da Saúde, houve uma abertura ainda maior para a comunicação acerca da sexualidade e IST's com as faixas etárias mais jovens (BRASIL, 2020).

Nesse âmbito, muitos idosos sequer haviam frequentado escolas até a adolescência, recevendo aconselhamentos diferentes ou mesmo inferiores acerca da sexualidade e suas práticas de forma segura. A população idosa, com ênfase nas idades mais avançadas, não teve o canal de comunicação sobre esse assunto acessível na juventude e, tampouco, durante o envelhecimento. Além disso, ainda hoje, permanece um tabu sociocultural que permeia o diálogo acerca do sexo na terceira idade, inclusive quando o interlocutor é o próprio idoso (UCHÔA et al, 2016).

Dessa forma, o foco dessa pesquisa foi analisar como se processava a construção de sentidos das idosas a partir dos aspectos de letramento em saúde, relacionando à temática da sexualidade e suas repercussões biopsicossociais, ou seja, avaliar a perspectiva individual desse grupo etário, a percepção única e individuada. A presente pesquisa possui um caráter interdisciplinar com ênfase nos trabalhos sobre educação em saúde, sexualidade, infecções sexualmente transmissíveis e estudos sobre letramentos. Esses enfoques transdisciplinares têm apresentado fundamentos importantes para discutir letramento crítico na sociedade contemporânea. Embora tenham despertado interesse da área de linguística aplicada, são ainda relativamente pouco explorados no Brasil, no que se refere à ressignificação do conceito e sua abrangência à área da saúde.

Espera-se elucidar a forma como ocorrem as experiências sexuais com o envelhecimento e instruir os cuidados em saúde necessários às práticas sexuais de forma segura aos idosos. Assim, com base em um diálogo empático, reforça-se a importância do cuidado e da proteção no quesito práticas sexuais na terceira idade, abordando a sexualidade no aspecto biopsicossocial, atuando inclusive na redução de IST's nessa faixa etária, ao mesmo tempo em que esta comunidade mantenha sua saúde sexual e autonomia preservadas, livre de estigmas e preconceitos. 


\section{MATERIAL E MÉTODOS}

O presente estudo é uma pesquisa qualitativa de natureza interpretativa e exploratória, com características da epistemologia da emergência pós-moderna (SOMERVILLE, 2008; MACIEL, 2016). Neste modelo de abordagem, os autores, de maneira passiva, ampliam possibilidades tanto para 0 redesenho de pesquisa quanto para a organização dos dados a serem analisados. A opção pela epistemologia da emergência se justifica pela possibilidade de deslocamento o olhar dos pesquisadores participantes para investigar aspectos que não foram consideradas previamente, bem como, contemplar maneiras não canônicas para o processo de coleta de dados.

A pesquisa foi realizada no Centro de Doenças Infecto-Parasitárias de Campo Grande - MS no entre os meses de janeiro a julho de 2019, com idosas que haviam recebido o diagnóstico de IST em algum momento da vida, cadastradas na unidade. As informações quanto ao diagnóstico e idade das pacientes foram conferidas pelo pesquisador a partir dos prontuários físicos. Os dados foram coletados por intermédio de entrevistas individuais, com duração de trinta minutos a uma hora, abordando as idosas no período entre as consultas médicas. Foram abordadas 15 idosas no período, porém, neste estudo foram analisados os relatos de cinco idosas que se destacaram. A pesquisa foi aprovada pelo Comitê de Ética em Pesquisa sistema CEP/CONEP e obteve aval da Secretaria Municipal de Saúde de Campo Grande/MS - SESAU/CG. A pesquisa foi realizada em conformidade com os preceitos éticos da Resolução do Conselho Nacional de Saúde (CNS) №. 466/12. 


\section{RESULTADOS E DISCUSSÃO}

Por meio das entrevistas, foi possível identificar comportamentos de risco inerentes às práticas sexuais apresentadas pelas idosas, semelhantes àqueles dispostos pelos jovens. No entanto, é evidente que há baixo letramento acerca dos riscos aos quais estão expostos, principalmente, acerca do uso de preservativos e transmissibilidade de IST's.

Não obstante, é visualizada uma negação pessoal com a prática sexual por alguns deles, seja por cunho religioso, ou relacionado às opiniões da família, medos e receios, ou até da própria construção do senso comum errôneo de que o idoso não realiza sexo devido ao envelhecimento dos órgãos genitais e, assim, se tornam disfuncionais por completo.

A Organização Mundial da Saúde define a saúde sexual como a abordagem positiva e respeitosa que possibilite a manutenção do afeto, o prazer e a segurança nas relações sexuais, isto é, com base em informações de qualidade, conhecimento acerca dos riscos e vulnerabilidades, assim como das consequências do sexo desprotegido, acesso ao serviço de saúde com atenção em saúde sexual e a vivência em um cotidiano que promova e afirme a saúde sexual. Assim, é factível que o meio social, englobando os serviços de saúde, veículos de informação em saúde e relações interpessoais interfiram ativamente no discernimento e na boa prática das relações sexuais. As políticas de saúde com atenção integral devem ser bem aconselhada, construídas e estimuladas dentre os idosos (OMS, 2017).

As entrevistadas mantêm uma relação saudável a nível emocional com seus parceiros, embora algumas relatem problemas na prática sexual, por diferentes motivos. Isso se torna visível dentre os relatos. A entrevistada 1, por exemplo, apresentava comportamento de risco para o contágio das IST's nos últimos anos, ao manter relações sexuais com mais de um parceiro sexual concomitante sem o uso de preservativo. Além disso, ela mantém relações conturbadas com o ex-marido que a deixou após tomar conhecimento que ela era portadora de HIV, há mais de 20 anos, ao mesmo tempo em que está casada com um senhor que está acamado e 
incapacitado de manter relações sexuais, impactando negativamente na sua vida sexual, conforme ela afirma. Portanto, ela não apresenta autopercepção de vulnerabilidade à contaminação por outras IST's, mesmo já sendo portadora de HIV.

\footnotetext{
Entrevistada 1: (...) Você vê né, eu to com esse veinho e ele tá com 72 anos. Ele tá comigo desde 2000, até meu marido era vivo ainda.

Pesquisador: Ele não tem Aids?

Entrevistada 1: Não ele não pegou Aids não, graças a Deus. Não o meu tá "anectado" já, o meu já sumiu já né. Como é que fala mesmo, tá "intubado" né, "incumbado", que não transmite mais, eu não transmito mais. Eu que não posso ser descuidada. Ele sabe que eu tenho a doença e respeita.

Pesquisador: Ele já fez exame?

Entrevistada 1: Vixe, já fez muito, sempre deu não reagente. Esse vô também já fez uns dez exame, esse veinho que tá lá em casa, tô pensando até em fazer de novo.
}

Nesse trecho, o depoimento nos faz entender que a carga viral está não detectada e, dessa forma, não seria transmissível, por isso ela afirma que não transmite mais e acredita que se curou da doença, se sentindo despreocupada. No entanto, a utilização do preservativo deve ser orientada, pois não há uma cura relatada do HIV e, ainda, há o risco de aumento da carga viral, ou até mesmo o acometimento de outras IST's. Assim, existe um entendimento interpessoal de respeito mútuo, entretanto falta conhecimento acerca dos riscos existentes durante a prática sexual e acerca da própria doença (BRASIL, 2018) (ANDRADE et al, 2019).

Pesquisador: E vocês aindam fazem sexo?

Entrevistada 1: Não (ênfase), ele tá doente, desde 2015 que ele capotou o carro, aí deu mal de Alzheimer e acabou. 0 bichinho tá se perdendo, não conhece nem eu mais, chega perguntando quem é você, fala: É a mamãe? Uma judiação.

O depoimento da idosa traz consigo a fragilidade decorrente do envelhecimento, associadas ao acometimento de disfunções sexuais, ou até doenças como a osteoporose, a sarcopenia, ou o Alzheimer como foi exposto por ela, dentre outras, que culminam com a perda da potência sexual e diminuição, ou até impossibilidade do ato (UCHÔA, 2016).

Pesquisador: Quando foi a última vez que vocês tiveram relação? 
Entrevistada 1: Com o senhorzinho faz tempo hein (risos). Depois de 2015 não fiz mais com ele, mas com esse ex-marido, que eu sou apaixonada por ele, esse cara é gente fina sabe, ele cuidou bastante de mim quando eu tava bastate doente sabe. Até hoje se eu quiser ele já quer me levar, ele é apaixonado por mim, inclusive eu falo, pode deixar que vou voltar pro meu senhorzinho, ele é aposentado e não vai me deixar faltar nada.

Pesquisador: Quando foi a última vez que fez sexo?

Entrevistada 1: Desde 2015 pra cá acabou, com esse marido, esse velho, ele pifou, foi a última vez. Depois desses tempo, umas poucas vezes que fui na casa do namorado, meu ex-marido, aí vai lá na casa da mãe dele. Só que ele é assim, ele não gosta de jogar lá dentro de mim, ele solta pra fora, ele que me ensinou isso aí também sabia. Ele fala - eu não sou besta- chegou a hora de gozar põe pra fora. $A$ última vez foi agora, esse ano, ah não, ano passado, esse ano não. Ele me chama pra ir na casa dele e eu fico com vergonha de ir na mãe dele lá né, aí quase não vou. Mas eu tô quase voltando com ele, ele é um bom marido.

Pesquisador: E como a senhora se sente, se sente satisfeita em relação à vida sexual?

Entrevistada: Essa doença, dá muita vontade, sabia. Tem época que dá uma vontade.

Pesquisador: E a senhora não faz?

Entrevistada 1: Não hahaha, com ninguém, eu morro de medo. Eu morro de medo de pegar uma doença em mim. Deusolivre um homem por aí tá com uma Aids bem forte e passa tudo pra mim, aí piora né.

Abordando mais pronunciadamente a sexualidade das entrevistadas, a entrevistada 1 afirma que a partir da incapacidade de seu marido atual manter relações sexuais, algumas vezes recorreu a relações extraconjugais para buscar sua satisfação pessoal. No entanto, a partir da "vergonha" e "medo" pessoais presentes, ela relata não ter prosseguido com as práticas sexuais de forma frequente, apesar de possuir a libido ativa, afetando-a psicologicamente, por não sendo capaz de se satisfazer adequadamente (SOARES; MENEGHEL, 2021).

Pesquisador: Mesmo com camisinha? A senhora já tentou obrigar eles a usar?

Entrevistada 1: Ah mas os homem hoje não quer por. Eu falo põe a camisinha já quer saber por quê quer por a camisinha, por que? Você tem doença?. Então né meu sobrinho um rapaz tão lindo, morre novinho Mas essa doença tá muito perigosa assim tudo. Eu por exemplo, queria falar pra doutora e doutor pra parar de tomar esses coquetéis, não aguento mais tomar. É muito ruim tomar, a gente toma e fica meia hora com a boca amarga, aí você tem que ficar chupando bala, comendo algum doce, porque vira um nojo a boca.

Pesquisador: Mas a senhora então não faz porque fica com esse medo? 
Entrevistada 1: É, fiquei com isso na cabeça. Eu pus na cabeça que eu não sirvo mais pra nada, que eu fiquei brocha, assim que eu fico e a médica falou que é da cabeça minha.

Alguns idosos aceitam as perdas funcionais existentes (SOARES; MENEGHEL, 2021). No entanto, nesse caso, ela refere uma perda funcional que pode não ser real de maneira orgânica, mas sim psicossocial. Por haver falta de discernimento, caracterizando baixo letramento em saúde, e estar exposta a relações negativas e não respeitosas, em detrimento do desempenho dos desejos, ocorrem prejuízos em sua saúde sexual e qualidade de vida como um todo (JÚNIOR, 2021).

Pesquisador: E a relação com seus filhos, é boa?

Entrevistada 1: Só uma que é boa. O César é muito bom pra mim. Ele sofreu acidente, quebrou a cabeça, ficou doente mental, ele é meio bipolar agora. O outro rapaz também é bipolar e epiléptico, mas não mora comigo não, ele bate em mim.

Nesse trecho, é demonstrada também a falta de apoio do núcleo familiar, que está colapsado. Dessa forma, a entrevistada expõe que vive em desamparo e até já sofreu violência doméstica. Assim, o idoso se torna vulnerável, principalmente, quando não está amparado por um ambiente infundado em boas vivências interpessoais.

Abordando os relatos de outros idosos, alguns acreditam que a falta de sexo não atrapalhe sua qualidade de vida. A exemplo disso, a Entrevistada 2 afirma que o respeito e amor pelo marido é superior aos desejos. Ela relata que irá buscar maneiras de contornar essa situação assim que a condição de saúde dele melhorar:

Pesquisador: Então a senhora não mantém relações sexuais hoje em dia?

Entrevistada 2: Não, com ele não, e pretendo com ninguém né. Eu respeito, vale muita coisa. Ele tá com problema por causa da cirurgia, ele tirou a próstata sabe.

Pesquisador: Tem algumas formas de melhorar isso, implantes, próteses, sabia?

Entrevistada 2: É, mas agora ele tá fazendo tratamento, indo pro médico, tempo a tempo sabe, daqui algum tempo quem sabe. A gente já ouviu falar, mas por enquanto ele ainda tá indo no médico. Vamo ver né, pra frente, mas graças a Deus a gente é um casal que se respeita, eu nunca ouvi falar nada dele e nem ele de mim, então é uma 
coisa assim né. Tenho e filhos, neta, um filho pastor, então é uma coisa que faz parte da vida da gente né. São tudo grandão já, só eu que sou baixinha.

Em geral, no contexto sociocultural midiático, é difícil encontrar conteúdos que relacionem práticas sexuais à terceira idade, desde a masturbação, sexo oral, sexo com penetração vaginal ou anal. Isso se torna um problema, já que não ocorre uma abordagem acerca desse assunto, com políticas que enfoquem na sexualidade desses indivíduos depois dos 60 anos, período em que a sexualidade permanece ativamente, culminando em pouco amparo por profissionais da saúde e por todos os indivíduos que os cercam. São escassos os canais de comunicação aos quais os idosos possam buscar para tratar de sua sexualidade com liberdade para enunciação das experiências e solução das dúvidas, com aquisição de conhecimento de qualidade, como proposto em saúde sexual. Inclusive, dentre os profissionais de saúde, este deveria ser um assunto discutido com maior frequência, eliminando quaisquer possíveis estigmas sociais (OMS, 2017; THEIS \& GOUVEIA, 2019).

Um dos aspectos recorrentes nos depoimentos de todas as entrevistadas foi a afirmação que, atualmente, ainda prevalecem os preconceitos acerca das IST's, embora tenham uma maior disponibilidade de conhecimento e visibilidade geral ao público acerca delas. Um aspecto alarmante na conversa com a entrevistada 1 foi 0 impacto gerado por ações preconceituosas e como isso a afetava diretamente. No exemplo a seguir, ela expõe que se sente mal ao ser indagada sobre os medicamentos que tomava e sua condição de saúde, ao afirmar que "são remédios pra diabetes". Isso, em âmbito ocupacional, além do meio social, gerou amplos impactos socioeconômicos à sua vida, sendo afastada de suas atividades laborais.

Pesquisador: Quando a senhora acha que contraiu a doença? Começou a sentir os sintomas?

Entrevistada 1: (...) Quando era um fim de ano, era aniversário dela, ela fez uma festa. Aí eu comi pelas coisalá e passei mal, passei mal, passei mal, quase morri, daí ela catou eu e levou no hospital. Chegou lá fizeram exame, e era a Aids. Ela me mandou embora na hora, disse pode pegar suas coisas e vazar, não quero você com Aids no meu salão de jeito nenhum, falou pra mim.

Entrevistada 1: (...) Outro dia no trabalho quando cheguei ouvi o pessoal conversando: "A gente ficou sabendo que você tem Aids é. Já 
vimos você tomando vários remédios". Eu falei logo: "Quem disse isso deve tá doido. É remédio pra diabetes". Não tem como, é muito preconceito, se eles soubessem me mandavam pra rua. No fim fiquei muito abalada e resolvi sai de lá, sentia que não era bem vinda.

As entrevistadas afirmam que a informação compartilhada acerca das afecções é muito superior ou até "mil vezes superior à antigamente". A empatia, entretanto, ainda é um ponto central a ser trabalhado em sociedade, pois foi possível visualizar, dentre os entrevistados, os impactos gerados pelo preconceito nos aspectos biopsicossociais de suas vidas. A partir dessas experiências negativas, a entrevistada 1 se demonstrou solidária com as pessoas, se dispondo a auxiliar no que for necessário para a evitar maiores danos àqueles indivíduos, como havia ocorrido com ela. Portanto, com base em um discurso empático, pode-se aprimorar o canal de comunicação com os idosos sobre a sexualidade e as IST's, podendo, assim, disseminar informação de qualidade, com enfoque na realização do sexo de forma segura, com o emprego de preservativos, diminuição de comportamentos de risco e, consequentemente, prevenção das IST's (AGUIAR et al, 2020).

\section{CONCLUSÃO}

Em relação à quebra de círculo hermenêutico interpretativo, ocorreram crises em diversos pontos das conversas: a continuidade da sexualidade na terceira idade, o baixo retrato pela mídia, em relação ao conceito e percepção das práticas sexuais e prevenção das IST's na terceira idade. A pesquisa ressignificou a visão dos pesquisadores a respeito do destaque que é dado à sexualidade do indivíduo idoso, tema ainda muito polemizado e pouco abordado, com baixa adesão nas unidades de saúde e mídia, em contraste com outros assuntos de costume. Nesse ponto, foi possível entender sobre as questões socioculturais e como elas influenciaram na prática sexual e como atingem os idosos atualmente. A extensão dessa subjetividade frente ao sexo e às práticas sexuais e prevenção de doenças, e como isso influencia na qualidade de vida e saúde, não eram resultados esperados. 
Trata-se de um tema relevante que merece maior reconhecimento, já que a prática sexual é realizada universalmente, tornando-se uma problemática de saúde coletiva. Por isso, como ponto importante de aprendizado com essa pesquisa, a área da saúde e educação devem dialogar e trabalhar em conjunto, para alavancar as ações e projetos de educação em saúde para a população idosa, sendo a base da prevenção primária, visto que a abordagem é direcionada frequente e unicamente aos jovens. São necessários mais estudos que correlacionem o letramento em saúde e a área das linguagens, bem como a discussão do papel dos profissionais da saúde nesse processo.

\section{REFERÊNCIAS BIBLIOGRÁFICAS}

AGUIAR, R. B.; et al. Conhecimento e atitudes sobre sexualidade em pessoas idosas com HIV. Ciênc. saúde coletiva 25 (6). Jun 2020. Disponível em: https://doi.org/10.1590/141381232020256.18432018. Acesso em: 18 de agosto de 2021.

ANDRADE, Juliane et al. Vulnerabilidade de idosos a infecções sexualmente transmissíveis. Acta paulista de enfermagem, São Paulo, vol.30, n.1, p.8-15, 2017. Disponível em: https://www.scielo.br/j/ape/a/NXypD4MRzpP6jtnp3xbHZHm/abstract/?lang=pt\#: : text=Associara m\%2Dse $\% 20$ de\%20forma\%20independente,quando\%20comparados\%20\%C3\%A0queles\%20s em\%20hist\%C3\%B3ria. Acesso em: 15 de jun. de 2021.

BRASIL. Políticas e diretrizes de prevenção das DST/aids entre mulheres. Secretaria Executiva, Coordenação Nacional de DST e Aids. - Brasília: Ministério da Saúde, 2003.

BRASIL. Protocolo Clínico e Diretrizes Terapêuticas para Atenção Integral às Pessoas com Infecções Sexualmente Transmissíveis (IST). Ministério da Saúde, Secretaria de Vigilância em Saúde, Departamento de Doenças de Condições Crônicas e Infecções Sexualmente Transmissíveis. Brasília: Ministério da Saúde, 2020.

BRASIL. Protocolo Clínico e Diretrizes Terapêuticas para Manejo da Infecção pelo HIV em Adultos. Ministério da Saúde, Secretaria de Vigilância em Saúde, Departamento de Vigilância, Prevenção e Controle das Infecções Sexualmente Transmissíveis, do HIV/Aids e das Hepatites Virais. Brasília: Ministério da Saúde, 2018.

BRITO, N. M. I. et al. Idosos, infecções sexualmente transmissíveis e aids: conhecimentos e percepção de risco. ABCS Health Sci, v.41, n.3, p.140-145, 2016. Disponível em: https://www.researchgate.net/publication/311688780_Idosos_Infeccoes_Sexualmente_Transmis siveis_e_aids_conhecimentos_e_percepcao_de_risco. Acesso em: 15 de jun. de 2021.

FERREIRA, C. de O.; et al. Vulnerabilidade a infecções sexualmente transmissíveis em idosos usuários de um centro de testagem e aconselhamento. Arq. Cienc. Saúde UNIPAR, Umuarama, v. 23, n. 3, p, 171-180, set./dez. 2019. Disponível em: https://www.revistas.unipar.br/index.php/saude/article/view/6757. Acesso em: 15 de jun. de 2021.

JÚNIOR, E. V. de S.; et al. Sexuality is associated with the quality of life of the elderly! Rev. Bras. 
Enferm. 74 (suppl 2), 2021. Disponível em: https://doi.org/10.1590/0034-7167-2020-1272. Acesso em: 18 de agosto de 2021.

MACIEL, R.; Por outras epistemologias de pesquisa em formação de professores. In: MARQUES, N. Da formação continuada aos momentos de tensão em sala de aula. Campinas: Pontes Editores, 2016.

MIRANDA, A. G.; et al. Políticas públicas em infecções sexualmente transmissíveis no Brasil. Epidemiologia e Serviços de Saúde 30 (spe1), 2021. Disponível em: https://doi.org/10.1590/S1679-4974202100019.esp1. Acesso em: 25 de julho de 2021.

OMS. Sexual health and its linkages to reproductive health: an operational approach. World Health Organization \& UNDP/UNFPA/UNICEF/WHO/World Bank Special Programme of Research, Development and Research Training in Human Reproduction. (2017). Disponível em: https://apps.who.int/iris/handle/10665/258738. Acesso em: 25 de julho de 2021.

SOARES, K. G.; MENEGHEL, S. N. O silêncio da sexualidade em idosos dependentes. Ciênc. Saúde Colet. 26 (01), Jan 2021. Disponível em: https://doi.org/10.1590/141381232020261.30772020. Acesso em: 18 de agosto de 2021.

SOMERVILLE, M. J. Waiting in the chaotic place of unknowing: articulating postmodern emergence. International Journal of Qualitative Studies in Education, v. 21, n. 3, p.209-220, May-June 2008. Disponível

em: https://www.researchgate.net/publication/248987071_'Waiting_in_the_chaotic_place_of_unknowi ng'_Articulating_postmodern_emergence. Acesso em: 15 de jun. de 2021.

THEIS, L. C.; GOUVÊA, D. L. Percepção dos Idosos em Relação a Vida Sexual e as Infecções Sexualmente Transmissíveis na Terceira Idade. R bras ci Saúde, v. 23, n.2, p.197-204, 2019. Disponível em: https://pesquisa.bvsalud.org/ripsa/resource/pt/biblio-1015130. Acesso em: 15 de jun. de 2021.

UCHÔA, Y. da S.; et al. A sexualidade sob o olhar da pessoa idosa. Rev. bras. geriatr. gerontol. Vol 19, n. 06. Nov-Dec 2016. Disponível em: https://doi.org/10.1590/198122562016019.150189. Acesso em: 18 de agosto de 2021. 